\title{
Multicentric B-cell Lymphoma and Disseminated Atherosclerosis in a Gelding
}

\section{Jedsada Siripoonsub ${ }^{1}$, Sirintra Sirivisoot $^{1}$, Sitthichok Lacharoje ${ }^{2}$, Somporn Techangamsuwan $^{1}$, AnUdep Rungsipipat $^{*}$}

${ }^{1}$ Companion Animal Cancer Research Unit, Department of Pathology, Faculty of Veterinary Science, Chulalongkorn University, Bangkok - 10330; ${ }^{2}$ Department of Pathology, Faculty of Veterinary Science, Chulalongkorn University, Bangkok-10330, Thailand.

\begin{abstract}
A 5-year old, 258-kg-weight, mixed thoroughbred gelding was found acute death with abdominal enlargement caused by hemorrhagic strangulated enteritis and colic. Necropsy and histopathology revealed multicentric lymphoma involving spleen and abdominal lymph nodes, disseminated atherosclerosis of vena cava, aorta and myocardium and metastatic calcification. Immunohistochemistry was performed in order to categorize immunophenotype of T-cell and B-cell lymphoma. This case was diagnosed as multicentric low grade B-cell lymphoma. In addition, pathogenesis of lymphoma associated with disseminated atherosclerosis of this case was discussed.
\end{abstract}

Keywords | Atherosclerosis, B-cell lymphoma, Equine, Multicentric lymphoma

Editor | Muhammad Abubakar, National Veterinary Laboratories, Islamabad, Pakistan.

Received | April 05, 2016; Accepted | April 21, 2016; Published | April 26, 2016

*Correspondence | Anudep Rungsipipat, Companion Animal Cancer Research Unit, Department of Pathology, Faculty of Veterinary Science, Chulalongkorn

University, Bangkok - 10330, Thailand; Email: Anudep.r@chula.ac.th

Citation | Siripoonsub J, Sirivisoot S, Lacharoje S, Techangamsuwan S, Rungsipipat A (2016). Multicentric B-cell lymphoma and disseminated atherosclerosis in a gelding. Res. J. Vet. Pract. 4(1): 11-16.

DOI | http://dx.doi.org/10.14737/journal.rjvp/2016/4.1.11.16

ISSN | 2308-2798

Copyright $(\subset 2016$ Siripoonsub et al. This is an open access article distributed under the Creative Commons Attribution License, which permits unrestricted use, distribution, and reproduction in any medium, provided the original work is properly cited.

$\mathrm{L}$ ymphoma is the most common hematopoietic tumor in horse worldwide. Its prevalence is quite low about $0.002-0.05 \%$ and $0.2-3.0 \%$, depending on the study, when compared with other domestic animals, such as cows, dogs, and cats. Lymphoma was reported in young and adult horse ranged in age 4 to 10 years (Taintor and Schleis, 2011). There is neither breed nor sex predisposition. Equine lymphoma is classified into multicentric, alimentary, mediastinum, cutaneous and solitary tumors of extranodal sites (Taintor and Schleis, 2011). Multicentric or generalized lymphoma is the most commonly reported form and involves multiple peripheral and internal lymph nodes and other organs (Germann et al., 2008; Trope et al., 2014; Westerman et al., 2014). The diagnosis of lymphoma in horse is always belated because of the lack of pathognomonic clinical sign. Histological classification of equine lymphoma was predominant phenotype of the neoplastic lymphocyte T- or B-cell (Durham et al., 2012). Multicentric T-cell lymphoma was found to be the most prevalent type of lymphoma (Durham et al., 2012; Canisso et al., 2013). The pathogenesis of systemic equine lymphoma remains obscure and there are currently no known risk factors.

Calcification of large arterial vessels, such as aorta, pulmonary artery, pulmonary artery branches, and carotid arteries, has been reported in horses (Arroyo et al., 2008; Martínez et al., 2012). In humans, medial artery calcification usually occurs as a degenerative process that becomes more severe with age (Teeter et al., 2010) whereas, it has been reported in horses at a relatively early age (5 years) and particularly in those with a racing background (Arroyo et al., 2008; Martínez et al., 2012). Four histologic patterns of arterial calcification in human patients have been categorized, namely atherosclerotic (fibrotic), medial artery calcification (Mönckeberg's sclerosis), cardiac valve, and vascular calciphylaxis (Teeter et al., 2010; Senba et al., 2012). 
The purpose of this report aimed to describe an unusual case in gross, microscopic lesions and immunophenotyping in a thoroughbred gelding affected by multicentric B-cell lymphoma and disseminated atherosclerosis.

A 5-year old, 258-kg-weight, mixed thoroughbred gelding was found acute death with abdominal enlargement. A day prior death, the horse remained appetite but stand still. In addition, routine hematology was performed for health monitoring two months prior death. The results revealed normal complete blood count $(\mathrm{CBC})$ with mild hyperphosphatemia (7.6; reference range 1.8-5.6 mg\%), high normal of serum globulin (4.7; reference $2.4-4.7 \mathrm{~g} \%$ ) and mild increased gamma-glutamyl transferase (GGT; 36; reference range 1-30 IU) (Meyer et al., 2006).

Following necropsy, visceral organs and affected tissue were preserved in $10 \%$ neutral buffered formalin, and then were submitted to Department of Pathology, Faculty of Veterinary Science, Chulalongkorn University for further investigation. Briefly, specimens were routinely histologic processed, embedded in paraffin wax and cut at 4-6 um. The sections were stained with Hematoxylin-Eosin (HE), Periodic acid Schiff (PAS) and Von Kossa.

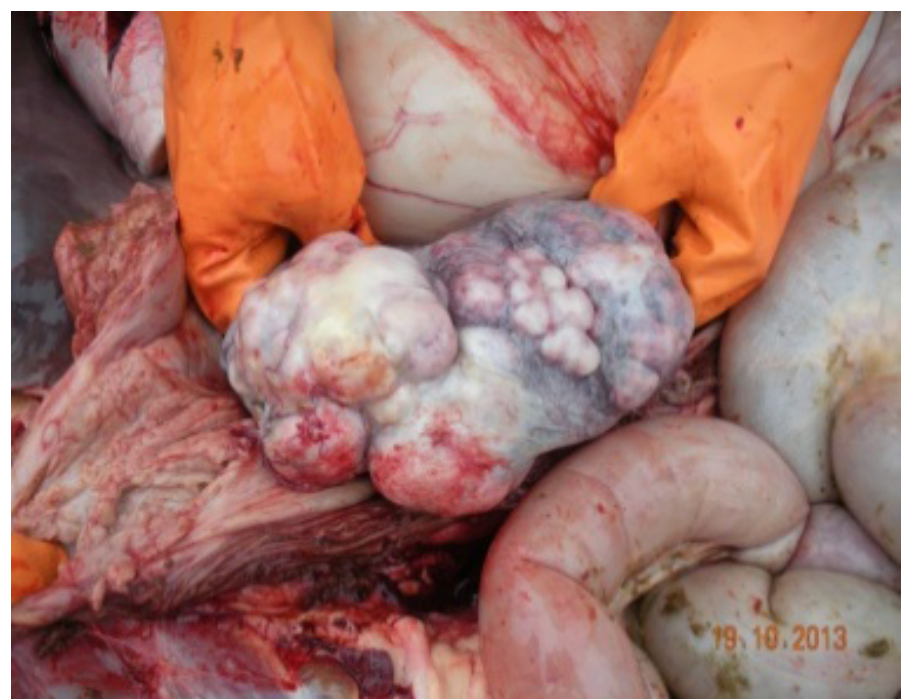

Figure 1: Multilobulated splenic mass $5 \times 5 \times 5 \mathrm{~cm}$ in size, white, and firm consistency

Immunohistochemistry (IHC) was performed by LSAB method for lymphoma cell type classification. Immunophenotype was done by using specific antibodies against T-cell (CD 3) (Rungsipipat et al., 2012) and B-cell (CD 79a) (Durham et al., 2012). Briefly, the sections were deparaffinized and antigen retrieval method was performed by using autoclave at $121^{\circ} \mathrm{C}$ for 5 minutes. Endogenous peroxidase enzyme was enhanced by incubation with $3 \% \mathrm{H}_{2} \mathrm{O}_{2}$ in methanol and nonspecific background was blocked by incubation with $1 \% \mathrm{BSA}$ at $37^{\circ} \mathrm{C}$ for 20 minutes. Primary antibodies against T-cell; monoclonal mouse CD3 antibody (Clone LN10, ready-to-use, Leica, UK) and poly- clonal rabbit CD 79 $\alpha$ ) (dilution 1:100, Dako, Denmark) were applied on slide and incubated at $4^{\circ} \mathrm{C}$ overnight. IHC reaction was developed by incubated slide with Envision Polymer (Dako, Denmark) at $37^{\circ} \mathrm{C}$ for 60 minute and visualized by 3 , diaminobenzidine tetrahydrochloride (DAB) and counterstained with Mayer's Hematoxylin. CD3 showed intense Intracytoplasmic positive staining whereas CD790 showed intense intracytoplasmic positive staining.

Upon necropsy, the most striking lesions were multiple white to yellow plaque and nodules, hard consistency and gritty with rough surface were found at outer surface of caudal vena cava, aortic valves and descending aorta. In hematopoietic system, spleen consisted of a $5 \times 5 \times 5-\mathrm{cm}$. large white solid mass with firm consistency and irregular shape (Figure 1) and multiple small nodules varying in size (range from 1-3 cm) on splenic capsule. Diffuse intraabdominal lymph nodes were dense, firm multilobulated enlarged recognized as generalized lymphadenopathy. Gastrointestinal tract revealed hemorrhagic strangulated enteritis associated with an $180^{\circ}$ - rotated transverse colon and bloating in large intestine. However, grasses fed at last night before death remained in the stomach and along the intestines with subserosal edema. Liver showed mild fatty change. Other organs that not stated were no remarkable lesions. Based on gross lesion, cardiogenic shock associated with respiratory failure from colic is presumptively suggested as a cause of death.

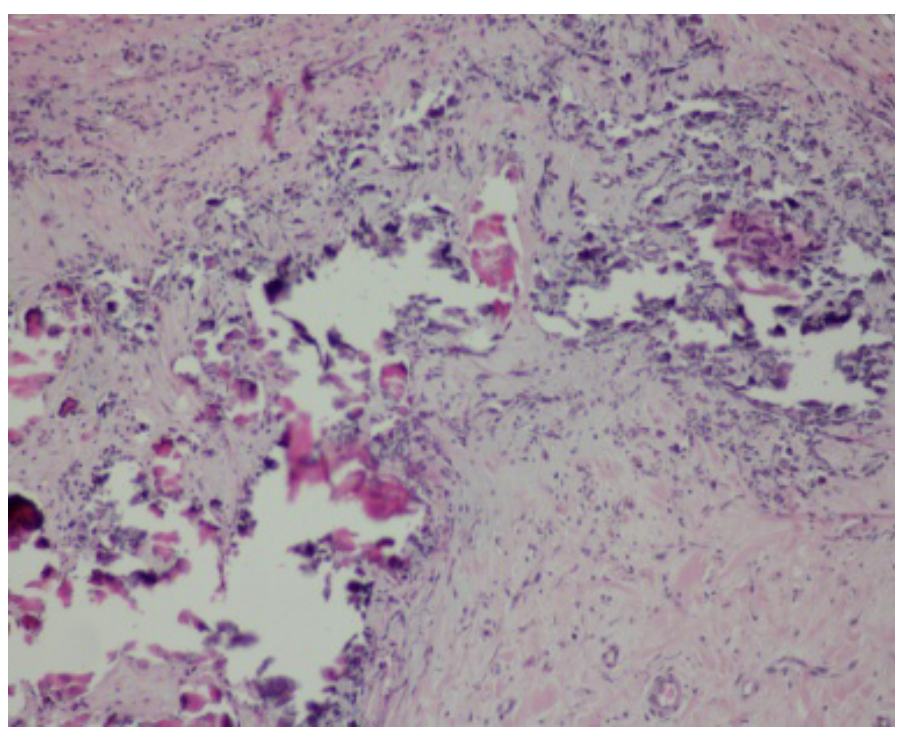

Figure 2: Multifocal dystrophic calcification at the endocardium of heart (HE stain, mag 40x)

Heart showed severe disseminated atherosclerosis at the tunica media of artery and arterioles; accumulation of deep basophilic, compacted acellular and amorphous substance at tunica media which were positive stained with Von Kossa, multifocal dystrophic calcification at the endocardium (Figure 2), myocardium and epicardium with lymphocytic infiltration and additionally, Sarcocystis spp. was frequently 
found in myocardium. Lung showed moderate degree of chronic interstitial pneumonia; characterized by increased numbers of proliferative pneumocytes type II at alveolar septum accompanied with increased collagen fibers at alveolar wall but no evidence of metastatic calcification was noted.

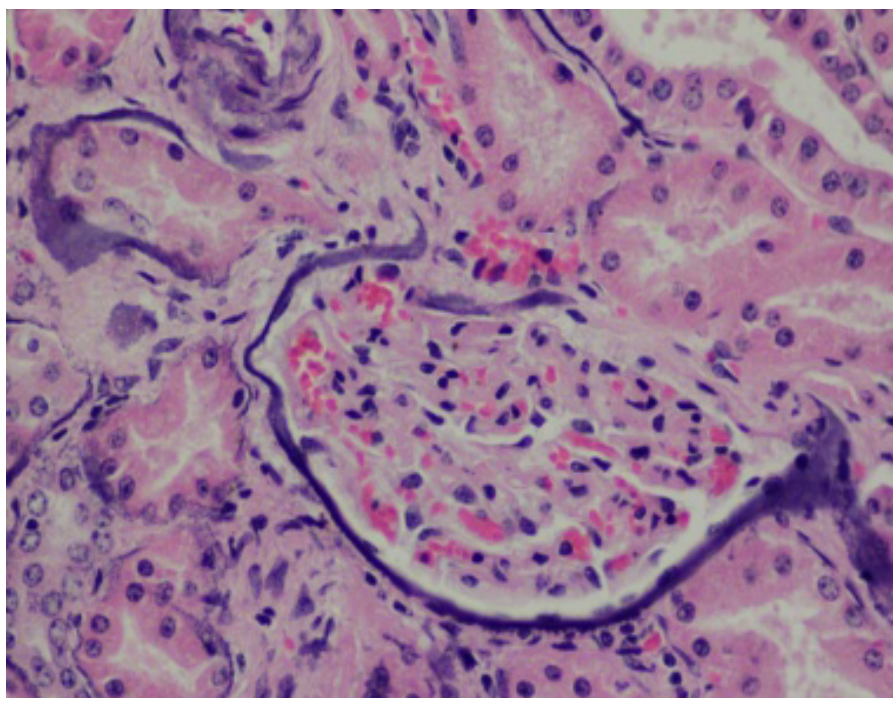

Figure 3: Metastatic glomerular and tubular basement calcification of kidney (HE stain, mag 40x)

Intestine revealed multifocal lymphocytic infiltration at lamina propria, multifocal atherosclerosis and severe submucosal hemorrhage. Kidney revealed diffuse metastatic calcification at glomerular basement membrane and renal tubular basement membrane (Figure 3) and mild focal infiltration of lymphocytes at interstitium.

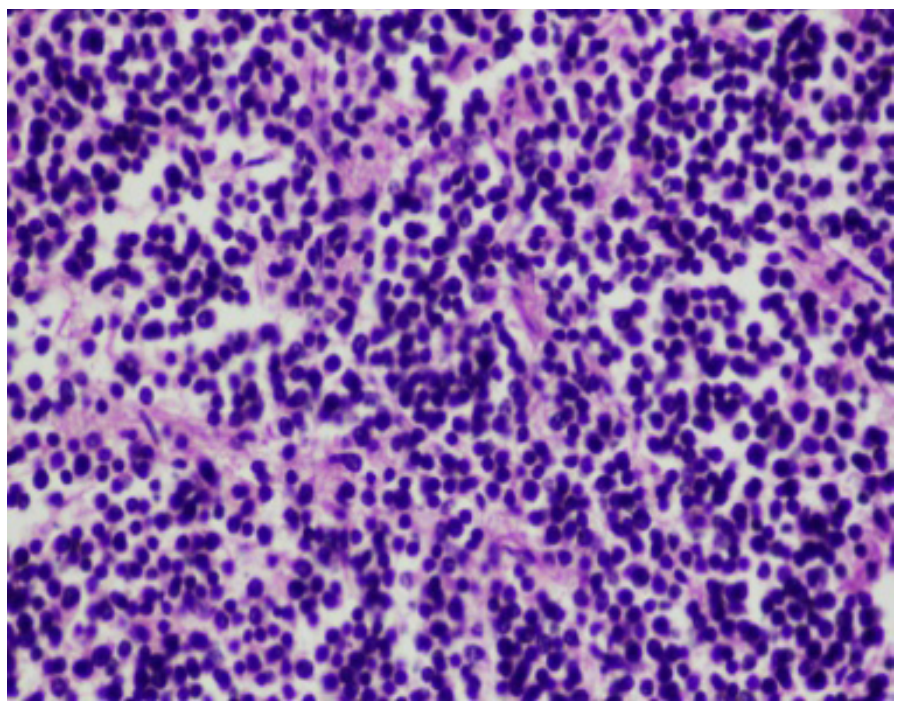

Figure 4: Lymph node consisted of mainly lymphoblasts and expanded lymphoid follicles. The tumor were small round cells with hyperchromatic round nuclei ( $\mathrm{HE}$ stain, mag 40x)

Lymph nodes showed diffuse expanded follicular pattern and dense solid sheets of lymphoblasts with fine fibrovascular stroma. The predominantly tumor cells were small to medium round shape, uniform in size and range from
5-7 um in diameter, scantly light basophilic cytoplasm and pleomorphic large round nuclei with 1-2 prominent nucleoli (Figure 4). The large lymphoma mass that attached at fibrotic splenic capsule consisted of lymphoblastic tumor cells resembling those in lymph node (Figure 5). Other lesions at spleen were diffuse metastatic calcification at periarterial sheath, splenic trabeculae and splenic capsule, diffuse splenic hemosiderosis. Immunohistochemistry was performed from lymph nodes and splenic mass. The tumor cells showed mainly CD79 $\alpha$ positive (B-cell marker), but not CD3 (T-cell marker) (Figure 6 and 7). Based on histopathological and immunohistochemistry, this case was diagnosed as multicentric low grade B-cell lymphoma. Additionally, this horse was affected by disseminated atherosclerosis and metastatic calcification.

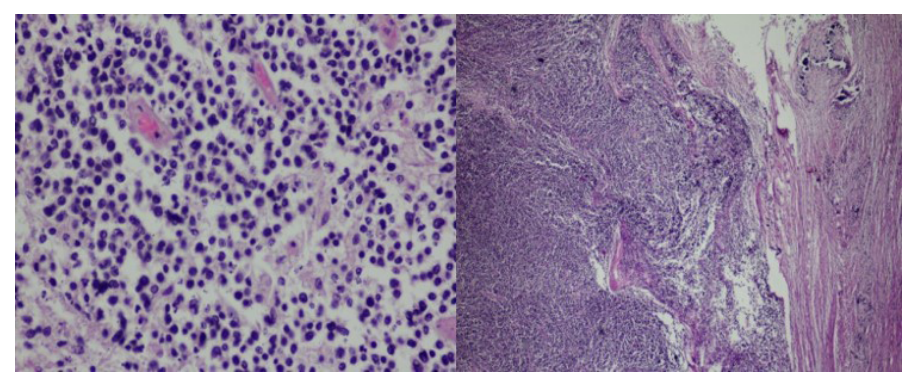

Figure 5: Splenic mass consisted of expanded follicular pattern and solid sheets of lymphoblasts attached at fibrotic splenic capsule (HE stain, mag 10x, 40x)

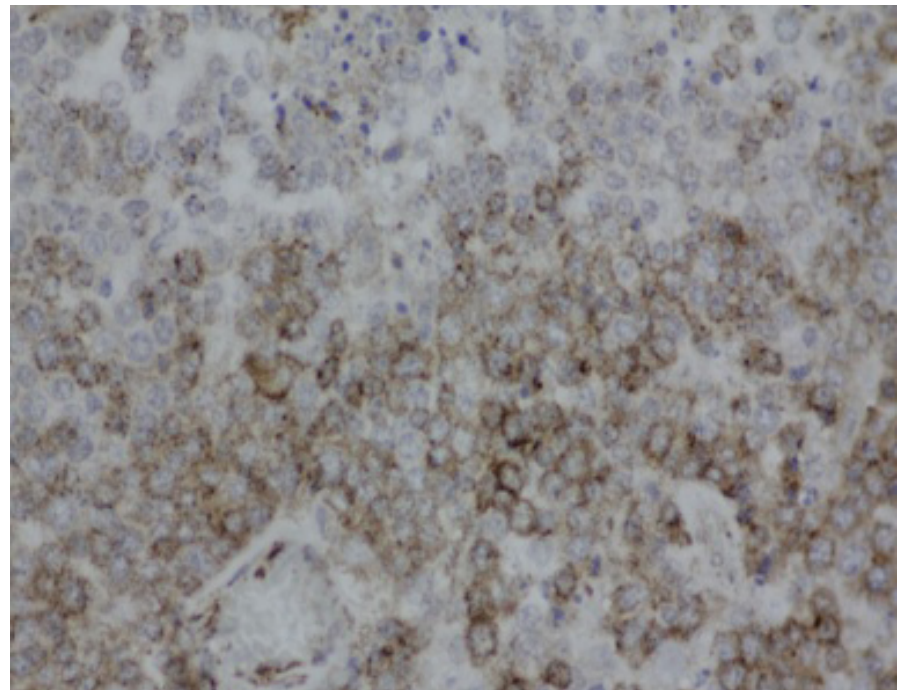

Figure 6: Intense positive staining of CD79 $\alpha$ (B-cell marker) of lymphoblasts in lymphadenopathy (LSAB, DAB counterstained with Mayer's Hematoxylin, mag 40x)

Multicentric B-cell lymphoma associated with disseminated atherosclerosis, metastatic calcification and Sarcocystic infection was diagnosed in this horse. The hematology profile of this case was similar to a previous report of multicentric lymphoma in horse (Taintor and Schleis, 2011; Doyle et al., 2013). Whereas, the most common clinicopathological features including hyperfibrinogenemia, hyperglobulinemia and hypoalbuminemia were not evident in 


\section{OPEN OACCESS}

this case. Fever is reported in approximately $50 \%$ of horses with lymphoma and is thought to be caused by tumor necrosis, pyrogens associated with neoplastic growth, and secondary infections (Kelley and Mahaffey, 1998; Cian et al., 2015). Lymphoma might be a possible cause of fever in this affected horse. Anemia was observed in approximately $1 / 3$ of horses with lymphoma and proposed causes include anemia of chronic inflammatory disease which is the most common cause, blood loss, IMHA hematopoietic dysplasia and leukoerythroblastic anemia (McGovern et al., 2011).

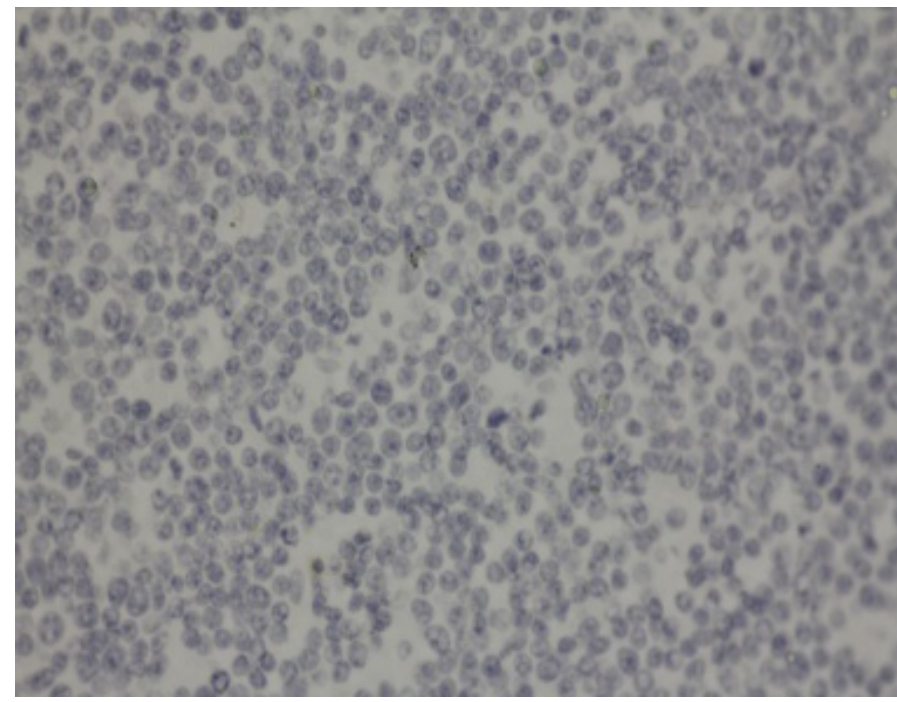

Figure 7: Negative staining of CD3 (T-cell marker) of lymphoblasts in splenic mass (IHC, LSAB, DAB counterstained with Mayer's Hematoxylin, mag 40x)

According to the WHO classification of hematopoietic tumors of domestic animals, leukemias and lymphomas derived from the same neoplastic clone are classified in the same category (B-cell or T-cell lymphoma). The neoplastic proliferation occurs primarily in lymphoid tissue of this case in spleen and intra-abdominal lymph nodes, This disease is referred to as lymphoma (Durham et al., 2012; Cian et al., 2015). In a previous report of 37 horses with lymphoma, 34 animals had tumors located in multiple lymphoid tissues plus abdominal or thoracic organs, and 3 horses were restricted to the skin and subcutis (Durham et al., 2012).

Immunophenotype results were not similar to previous reports of immunophenotyping of equine lymphomas, suggesting that multicentric, alimentary and mediastinal lymphomas are most frequently of T-cell origin (Durham et al., 2012). The most common subtype of lymphoma in the horse is T-cell-rich, B-cell lymphoma (La Perle et al., 1998; Kelton et al., 2008; Westerman et al., 2014). Durham et al. (2012) identified T-cell-rich, B-cell lymphoma as the most common subtype in 87 of 203 cases reported. Others reported T-cell lymphoma as the most common subtype in horse (Lehmbecker et al., 2014; Trope et al., 2014). The tumor described here was identified as being of B-cell origin (strongly positive with CD79 $\alpha$ and negative for CD3 immunophenotype), which is contrast with a previous report of a malignant equine $\mathrm{T}$-cell lymphoma. The choice of CD3 and CD79 $\alpha$ antibody application was proven to use as routine diagnostic laboratory to identify subtype in horse as well as in human being and canine counterparts.

Clinical signs of lymphoma reflect dysfunction of affected organs and the course of the disease is typically rapid once. In the presented horse, postmortem evaluation revealed that multiple organ dysfunction including spleen, mesenteric lymph nodes were involved. This horse was suffered from hemorrhagic strangulated enteritis associated colic causing fatal death. Diffuse mesenteric lymphadenopathy might be a major cause of this syndrome.

Metastatic calcification in human lymphoma was reported and commonly seen in alveolar septa and myocardium but mostly showed hypercalcemia (Senba et al., 2012). The morphologic similarities suggest a similar pathogenesis, but the initiating causes are likely different for 2 reasons. First, medial artery calcification occurred at a relatively early age in horses, whereas, in humans, it mainly occurs in older individuals. Second, the anatomic distribution of lesions is different; in humans, medial artery calcification can be observed in the aorta and in coronary, carotid, renal, and iliac arteries, whereas, in horses, the pulmonary arteries are the most obviously affected. Medial calcification of the aorta can be induced experimentally in animals by means of vitamin D overdose in rats, pigs, and rabbits; vitamin D combined with nicotine in rats and rabbits; vitamin $\mathrm{D}$ and magnesium deficiency in pigs; or models of renal failure in rats and rabbit (Fales-Williams et al., 2008).

Differential diagnoses for arterial medial calcification in humans include systemic effects of abnormal regulation of $\mathrm{pH}$, electrolytes, or metabolic disorders. Specific examples include hypervitaminosis $\mathrm{D}$, uremia from chronic renal disease, chronic dysregulation of hyperglycemia from diabetes mellitus, dysregulation of parathormone, hyperparathyroidism, and idiopathic arterial calcification (Harmeyer et al., 2004; Hellemons and Bakker, 2010; Teeter et al., 2010). Evidence of hyperphosphatemia associated with metastatic calcification in this horse was noted. High phosphorus contained in concentrate induced secondary nutritional hyperparathyroidism was reported. Atherosclerosis and metastatic calcification in this case might be described both in term of nutritional hyperparathyroidism and lymphoma induced hypercalcemia of ma- 


\section{OPEN OACCESS}

lignancy. Previous report in one horse, the horse was mildly hyperphosphatemia, normocalcemia, polyurea, polydipsia, and moderately azotemia. Six months later, at the time of euthanasia, the horse was normocalcemia and mildlyhypophosphatemia, with normal PTH concentrations and presumed normal levels of 25-hydroxyvitamin D. However, these hypotheses should be further investigated.

In conclusion, this present case a horse suffered from multicentric B-cell lymphoma associated with atherosclerosis and metastatic calcification was noted. The pathogenesis of lymphoma induced hypercalcemia of malignancy was quite interesting.

\section{ETHICALLY APPROVED}

This article does not contain any studies with human participants or experimental animals performed by any of the authors.

\section{CONFLICT OF INTERESTS}

The authors declare that they have no financial or personal relationship(s) which may have conflicts of interests them in writing this article.

\section{ACKNOWLEDGEMENTS}

This work was supported by Companion Animal Cancer Research Unit, Department of Pathology, Faculty of Veterinary Science, Chulalongkorn University, Bangkok 10330, Thailand.

\section{AUTHOR'S CONTRIBUTION}

All authors contributed equally in all details of this manuscript.

\section{REFERENCES}

-Arroyo LG, Hayes MA, Delay J, Rao C, Duncan B, Viel L (2008). Arterial calcification in race horses. Vet. Pathol. 45: 617-625. http://dx.doi.org/10.1354/vp.45-5-617

- Canisso IF, Pinn TL, Gerdin JA, Ollivett TL, Buckles EL, Schweizer CM, Ainsworth DM (2013). B-cell multicentric lymphoma as a probable cause of abortion in a quarter horse brood mare. Can. Vet. J. 54: 288-291.

- Cian F, Tyner G, Martini V, Comazzi S, Archer J (2015). Leukemic small cell lymphoma or chronic lymphocytic leukemia in a horse. Vet. J. Clin. Pathol. 42(3): 301-306. http://dx.doi.org/10.1111/vcp.12057

-Doyle AJ, MacDonald VS, Bourque A (2013). Use of lomustine (CCNU) in a case of cutaneous equine lymphoma. Can. Vet. J. 54: 1137-1141.

-Durham AC, Pillitteri CA, Myint MS, Valli VE (2012).
Two hundred three cases of equine lymphoma classified according to the World Health Organization (WHO) classification criteria. Vet. Pathol. 50(1): 86-93. http:// dx.doi.org/10.1177/0300985812451603

-Fales-Williams A, Sponseller B, Flaherty H (2008). Idiopathic arterial medial calcification of the thoracic arteries in an adult horse. J. Vet. Diagn. Invest. 20: 692-697. http://dx.doi. org/10.1177/104063870802000533

- Germann SE, Richter M, Schwarzwald CC, Wimmershoff J, Spiess BM (2008). Ocular and multicentric lymphoma in a young racehorse. Vet. Ophthalmol. 11(Suppl) 1: 51-56.

- Harmeyer J, Schlumbohmb C (2004). Effects of pharmacological doses of vitamin D3 on mineral balance and profiles of plasma vitamin D3 metabolites in horses. J. Steroid Biochem. Mol. Biol. 89-90: 595-600. http://dx.doi.org/10.1016/j. jsbmb.2004.03.034

-Hellemons ME, Bakker SJL (2010). Vitamin D as an accelerator of atherosclerotic calcification: a D-tail that may be a Trojan horse. Diabetologia. 53: 2688. http://dx.doi.org/10.1007/ s00125-010-1928-0

-Kelley LC, Mahaffey EA (1998). Equine malignant lymphomas: morphologic and immunohistochemical classification. Vet. Pathol. 35(4): 241-252. http://dx.doi. org/10.1177/030098589803500402

-Kelton DR, Holbrook TC, Gilliam LL, Rizzi TE, Brosnahan MM, Confer AW (2008). Bone marrow necrosis and myelophthisis: manifestations of T-cell lymphoma in a horse. Vet. Clin. Pathol. 37(4): 403-408. http://dx.doi. org/10.1111/j.1939-165X.2008.00069.x

-La Perle KM, Piercy RJ, Long JF, Blomme EA (1998). Multisystemic, eosinophilic, epitheliotropic disease with intestinal lymphosarcoma in a horse. Vet. Pathol. 35(2): 144146. http://dx.doi.org/10.1177/030098589803500209

-Lehmbecker A, Liebing J, Barthel Y, Habierski A, Cavalleri J, Puff C, Rademacher B, Lumpe S, Beineke A (2014). Neurolymphomatosis in three horses with multicentric T-cell-rich B-cell lymphoma. J. Comp. Pathol. 151: 181185. http://dx.doi.org/10.1016/j.jcpa.2014.04.004

- Martínez J, Montgomery DL, Uzal FA (2012). Vascular mineralizationin the brain ofhorses.J.Vet.Diagn.Invest.24(3): 612-617. http://dx.doi.org/10.1177/1040638712442352

-McGovern KF, Lascola KM, Davis E, Fredrickson RL, Tan $\mathrm{R}$ (2011). T-cell lymphoma with immune-mediated anemia and thrombocytopenia in a horse. J. Vet. Intern. Med. 25: 1181-1185. http://dx.doi.org/10.1111/j.19391676.2011.00777.x

- Meyer J, DeLay J, Bienzle D (2006). Clinical, laboratory, and histopathologic features of equine lymphoma. Vet. Pathol. 43: 914-924. http://dx.doi.org/10.1354/vp.43-6-914

-Rungsipipat A, Chayapong J, Jongchalermchai J, Thongruk T, Manachai N, Wangnaitham S, Techangamsuwan S (2012). Histopathological classification and immunophenotyping of spontaneous canine lymphoma in Bangkok metropolitan. Comp. Clin. Path. 23: 213-222. http://dx.doi.org/10.1007/ s00580-012-1600-9

-Senba M, Kawai K, Mori N (2012). Pathogenesis of metastatic calcification and acute pancreatitis in adult T-cell leukemia under hypercalcemic state. Leukemia Res. Treat. 2012; 128617-9. http://dx.doi.org/10.1155/2012/128617

-Taintor J, Schleis S (2011). Equine lymphoma. Equine Vet. Edu. 23(4): 205-213. http://dx.doi.org/10.1111/j.20423292.2010.00200.x

- Teeter MG, Arroyo LG, Bakker JD, Hayes MA, Viel L, 
Runciman RJ (2010). Finite element analysis of wall stress in the equine pulmonary artery. Equine Vet. J. 42(1): 68-72. http://dx.doi.org/10.2746/042516409X464131

-Trope GD, Mc Cowan CI, Tyrrell D, Lording PM, Maggs DJ (2014). Solitary (primary) uveal T-cell lymphoma in a horse. Vet. Ophthalmol. 17(2): 139-145. http://dx.doi. org/10.1111/vop.12078

-Westerman TL, Poulsen KP, Schlipf Jr JW, Valentine BA (2014). Neurotropic T-cell-rich B-cell lymphoma in a 14-year-old Morgan gelding. Can. Vet. J. 55: 379-382. 